\title{
Prevalence of Hepatitis-B infection among Pregnant Women in a Primary Healthcare Centre in Abuja, Nigeria
}

\author{
Article by Orji Ikechukwu Anthony ${ }^{1}$, Okoli Ugochukwu Thompson ${ }^{2}$ \\ ${ }^{1}$ Disease Control Unit, Health Department, AMAC, Abuja, Nigeria \\ ${ }^{2}$ Clinical Services Department, Lighthouse Medicare Services Ltd. Abuja, Nigeria \\ E-mail:drtony2013@gmail.com,drtonyiyke@gmail.com
}

\begin{abstract}
Background: Hepatitis B is adjudged to be one of the most infectious diseases in the world and a major public health problem with about 5\% of the world population as asymptomatic carriers translating to 350 million people harboring hepatitis B virus (HBV) globally. Chronic infection with HBV occurs in up to $90 \%$ of infants infected at birth, 30\% for children aged one year to five years, and 6\% from six years and above. Thus, prevention of perinatal infection is an important strategy to reducing the prevalence of chronic hepatitis B infection in Nigeria being an endemic country. Emphasis therefore is placed on the screening of all pregnant women for HBsAg during the antenatal visit so as to detect positive women whose new borne will need prophylaxis to reduce the risk of contracting the infection.

Objectives: 1. to determine the percentage of pregnant women who were screened for Hepatitis B at PHC Karu, Abuja in 2013.2. To determine the sero-prevalence of Hepatitis B among pregnant women screened at PHC Karu, Abuja, in 2013.3. To determine whether the policy of prophylaxis against peri-natal infection for neonates of sero-positive mothers were strictly followed at this PHC during the review period.

Methods: This is a retrospective cross-sectional study which used secondary data extracted from antenatal registers, laboratory registers, HBsAg-positive patients' antenatal and delivery case notes for the period under review - Jan.-Dec. 2013.

Results: All the 856 pregnant women who registered for ANC in this PHC were offered HBsAg screening, 99.3\% (850) complied with the screening, and 8.5\% (72) sero-prevalence recorded. All the positive cases were referred to secondary health facility for HBIG prophylaxis; however no follow-up was done to ascertain the outcome.

Conclusion: The high endemic rate of $H B V$ infection, (8.5\% prevalence) requires more effort at preventing the vertical transmission. $100 \%$ screening rate for all ANC clients is highly encouraged as well as 100\% follow up rate for exposed infants' HBIG prophylaxis.
\end{abstract}

Keywords: Prevalence, asymptomatic, HBV infection, pregnant women, Primary Healthcare Centre, HBsAg screening.

\section{Acronyms}

$\begin{array}{lll}\text { ANC } & : & \text { Ante Natal Care } \\ \text { AMAC } & : & \text { Abuja Municipal Area Council } \\ \text { CDC } & : & \text { Centers for Disease Control and Prevention } \\ \text { DNA } & : & \text { Deoxyribonucleic Acid } \\ \text { HBcAg } & : & \text { Hepatitis B core antigen } \\ \text { HBIG } & : & \text { Hepatitis B Immunoglobulin } \\ \text { HBsAg } & : & \text { Hepatitis B surface antigen } \\ \text { HBV } & : & \text { Hepatitis B Virus } \\ \text { PHC } & : & \text { Primary Healthcare Center } \\ \text { USPSTF } & : & \text { U.S. Preventive Services Task Force } \\ \text { WHO } & : & \text { World Health Organization }\end{array}$


Texila International Journal of Public Health

Volume 4, Issue 4, Dec 2016

\section{Background}

Hepatitis B surface antigen (HBsAg) formerly called Australian antigen because it was first described in the serum of an Australian aborigine in 1963 and in 1968, the Australian antigen was discovered to be related to type B hepatitis (Emechebeet., al 2009). According to the work by Emechebe et.al, they reported that David S. Dane, a $20^{\text {th }}$ century English Virologist found virus-like particles in the serum of patients suffering from type B hepatitis in 1973 and these particles were designated as the hepatitis B virus (HBV) also called Dane particles. Hepatitis B is adjudged to be one of the most infectious diseases in the world and a major public health problem with about $5 \%$ of the world population as asymptomatic carriers translating to 350 million people harboring hepatitis B virus (HBV) globally (Aminuet., al 2013). The WHO report on HBV stated that, a global mapping can categorize the world into three as regards the prevalence of chronic Hepatitis B infection. These are high $(>8 \%$ prevalence), intermediate ( $2-8 \%$ prevalence), and low ( $<2 \%$ prevalence), thus by this classification, Nigeria is a high endemic area. Furthermore, Aminuet., al (2013) indicated that Chronic HBV infection is a major risk factor for deaths from cirrhosis and liver cancer and the infection has reached hyper-endemic levels in Nigeria with the sero-prevalence of hepatitis B virus surface antigen (HBsAg) estimated to range from $10 \%$ to $40 \%$.

Lin K. \& Vickery J. (2009) stated that in 2004, the U.S. Preventive Services Task Force (USPSTF) recommended that exposure to Hepatitis B virus infection should be screened for every pregnant woman when they attend their first ante-natal clinic. To do this screening, HBsAg strip test should be used. This recommendation was based on screening on evidence that this screening when followed-up with preventive vaccination of neonates born to HBsAgpositive mothers will substantially reduce the risk for chronic HBV infection among these children. Thus in order to reduce mother to child transmission of Hepatitis B, the passiveactive immunization strategy with Hepatitis B immune globulin and Hepatitis B vaccine at birth for the neonates born to Hepatitis B positive women is widely recommended. This recommendation is found in the Australian National Antenatal care guidelines, UK's National collaborative center for women's and children's health and the U.S preventive services task force.

In Nigeria, this guideline is adopted, emphasizing the screening of all pregnant women for Hepatitis B surface antigen during the antenatal visit so as to detect positive women whose new borne will need prophylaxis because they are at higher risk of contracting the infection from vertical transmission. How is the Primary Healthcare Centre (PHC) carrying out this role of screening the pregnant women during antenatal visits? What percentage of the clients test positive to Hepatitis B surface antigen? What was done for the new borne of positive mothers? These questions were what prompted this study.

Objectives of the study: 1 . to determine the percentage of pregnant women who were screened for Hepatitis B at PHC Karu, Abuja, from January-December 2013.2. To determine the sero-prevalence of Hepatitis B among pregnant women screened at PHC Karu, Abuja, from January-December 2013.3. To determine whether the policy of prophylaxis against perinatal infection for neonates of sero-positive mothers were strictly followed at this PHC during the review period.

\section{Literature review / general considerations}

Hepatitis B Infection: Formerly known as 'serum' hepatitis, hepatitis B infection is an acute systemic viral infection with major pathology in the liver, caused by hepatitis B virus (HBV) and transmitted usually through the parenteral route (Park, 2007). According to WHO (2014), Hepatitis B virus is a double stranded DNA virus from the hepadnaviridae family. It measures about 42nm and has a nucleocapsid core, the 'HBcAg' measuring about 27nm. These are surrounded by outer envelope made of lipoprotein. This outer coat contains the Hepatitis B surface antigen (HBsAg).Viral hepatitis B infection represents a serious worldwide public health problem, a disease often under diagnosed in the tropics since hepatitis B infection represents only one of the several pathologic conditions which may 
result in liver damage (Azubike \& Nganginieme, 1999).Park (2007) gave a succinct picture of the characteristics \& possible sequelae of hepatitis B infection as he explained that the disease is characterized by a tendency to long incubation ranging from 6 weeks to 6 months and a protracted illness with a variety of outcomes. Usually acute self-limiting infection (80-95\%), which may be subclinical or asymptomatic in some cases with about 5-15\% failing to resolve, thus leading to persistent carrier state. He further stated that persistent chronic hepatitis may lead to progressive liver disease including chronic active hepatitis and hepatocellular carcinoma.

Epidemiology: Hepatitis B infection is a globally endemic disease occurring more in the tropical and developing countries. More than 2 billion people worldwide have been infected at one point in their life with about 350million chronic carriers (Park, 2007). The carrier state is defined as the presence of HBsAg for more than 6 months (Lucas \& Gilles, 2003). The disease prevalence has been grouped into; 1 . low endemic ( $<2 \%$ prevalence), 2 . intermediate endemic, (2-8\% prevalence), 3. high endemic ( $>8 \%$ prevalence). The prevalence varies from region to region and countries with high standard of personal and environmental hygiene tend to have low prevalence of the disease for example, $0.1 \%$ prevalence is recorded in some European countries while up to $15 \%$ prevalence were found in some tropical countries (Lucas and Gilles, 2003).Different authors have recorded varying prevalence rates from studies done in Nigeria ranging from; 37-46\% (Azubike \& Nganginieme, 1999), 9-39\% (Emechebe et.al, 2009), $10-40 \%$ (Aminu et.al. 2013). Thus, it is an obvious fact that prevalence rate in Nigeria is above $8 \%$, making it one of high endemic countries of the world. For infants infection, those infected at birth has been shown to be more prone to developing chronic infection as stated by Emechebe et.al., (2009), Chronic infection with HBV occurs in up to $90 \%$ of infants infected at birth while children aged one year to five years, there infection leads to about on $30 \%$ chronicity and the figure drops further in children aged six years and above with only about 6\% developing chronic infection. Therefore, prevention of perinatal infection is an important strategy to reducing the prevalence of chronic hepatitis B infection in Nigeria. Transmission; Hepatitis B transmission is blood borne, transmitted by inoculation as stated by Lucas and Gilles (2003). Transmission may occur by ; transfusion of blood or blood products, accidental inoculation e.g. shared use of unsterilized hypodermic needles drug addicts, mass immunization, tattooing, ritual scarification, other modes are through insect bites, vertical transmission from carrier mother during perinatal period, sexual intercourse (heterosexual \& homosexual), serous exudates of skin ulcers (direct contact inoculation), \& injury -associated sports (Lucas \& Gilles, 2003). The high risk groups are health workers, haemophiliacs, haemodialysis patients, sexually promiscuous, homosexuals, and Intra Venous drug users (Longmore et.al. 2001). Babies born to Hepatitis B carrier women are also at high risk of infection (Collier et.al. 2003). Though, vertical transmission from infected mother is high risk route of infection, available studies has shown a rather low transmission rate of 2.8\% by Abdulsalam et, al., (1986). However, considering high fertility rate of Nigeria, this will be translated to a very high number of children. Incubation Period; Longmore et.al,(2001) stated that the incubation period is 30days to 180days. However, Park (2007) related the median incubation period to be lower than 100 days (range 45 to 180 days). He explained that lower doses of the virus tend to result in longer incubation period. Clinical picture; Prodromal symptoms include fever, malaise, anorexia, nausea, arthralgia. Jaundice with or without hepatomegaly, splenomegaly, adenopathy and urticaria, (Longmore et.al, 2001). The picture can be complicated by carrier state and chronic liver disease which may follow infection. Chronic liver disease may be severe, may progress to primary liver cancer (Park, 2007). For diagnosis, there are three distinct antigen-antibody systems that relate to HBV infection and a variety of circulating makers that are useful in diagnosis.

Treatment: The treatment is supportive; alcohol should be avoided as well as other hepatotoxic drugs. Chronic HBV may respond to interferon alpha or other antiviral drugs like lamivudine, famciclovir, (Longmore et.al, 2001). 
Prevention and Containment: Prevention has been a major aim in managing viral hepatitis B. Three broad strategies are: health education, screening and vaccination. 1. Health education; Enlightenment of the general public on the various modes of transmission and preventive measures will go a long way towards preventing the spread especially in resource limited setting (Emechebe et.al. 2009). 2. Screening; Screening of all pregnant women is now recommended (Collier et.al, 2003). The aim is to detect positive client for adequate prophylaxis for their new borne. Also sexual partners of any positive client should also be screened and vaccinated. Screening is also recommended for all donors of blood before bleeding and screening of all blood and blood products before transfusion. Hepatitis B Vaccine; There is active vaccination done with older plasma derived vaccine and the newer Recombinant DNA vaccine. It is given at day 0,1 month \& 6month intervals. There is also passive vaccination with Hepatitis B immunoglobulin (HBIG), in addition, there is a combination of the two vaccines, active -passive immunization. It's recommended to vaccinate all children within the first year of life and this has been incorporated into the immunization schedule (Lucas\& Gilles, 2003). Infants of known carriers should be given passive -active immunization, HBIG within 12hours of birth and Hepatitis B vaccine within 7days of birth (Collier et.al, 2003).Health workers and other members of at risk group should be vaccinated (Lucas \& Gilles, 2003).

\section{Methods}

This is a retrospective cross-sectional study which used secondary data extracted from antenatal registers, laboratory registers, HBsAg-positive patients' antenatal and delivery case notes for the period under review - Jan.-Dec. 2013 at the health center. The study area is primary Health Center, Karu, (AMAC),in Abuja, Nigeria. The site was selected by purposive sampling. This technique was used in order to select a Primary Health Center with high volume of ANC client's turnover to get a sizable number of participants, enough, to validate the study as well as one with functional laboratory and qualified personnel running the HBsAg laboratory tests. Primary Health Center, Karu fulfilled these criteria and thus was selected. The Study Population involved all pregnant women who attended ANC at the health center from January to December, 2013. The total Population Sampling method was used in order to actualize the objective of measuring the prevalence of chronic HBV infection among the pregnant women attending ANC at the Centre. While the 2013 ANC register was the sampling frame, the sample size was all the 856 pregnant women who attended ANC at the center during the review period. The strategy for data extraction consists of the following: Firstly, the antenatal booking (first visit) register was reviewed, to ascertain the number of patients that were booked from $1^{\text {st }}$ January 2013 to $31^{\text {st }}$ December 2013. Note that the policy of this PHC is that all the pregnant women were referred to the laboratory section for routine ANC test which includes HBsAg screening on their first visit. The result will be evaluated on their second visit. Secondly, the ANC register was used to compare with the Laboratory register for recording routine ANC results in order to check if all the women actually did the test or otherwise. Thirdly, the Laboratory register was used to check the number of women whose HBsAg test results were negative and those that were positive. Fourthly, the case notes of the patients whose results were positive were reviewed to find out the plan/ line of management for prophylaxis against HBV infection as documented in the case notes. Exploratory method of data analysis was employed in the study, using simple arithmetic and easy- to-draw charts to summarize data. The results were reported in the form percentages and presented using pie bar and column charts.

\section{Ethical Clearance}

Ethical approval was given by the ethical committee of the Health Department, Abuja Municipal Area Council (AMAC), Federal Capital Territory, Nigeria. The confidentiality of patient's information was maintained through the research process. 


\section{Results}

1. Demographics of the sample population revealed the distribution of the age of respondents as $31 \%$ from age group of $25-29$ (highest), $29 \%$ for $20-24$ years, $20 \%$ for 30-34 years, $15 \%$ for $14-19 y e a r s$ and $5 \%$ for 35-43years (table 1). While the occupational distribution as shown in table 2, revealed the highest group to be Public servants at $45 \%$, Traders (22\%), House Wives (18\%) and Farmers (15\%).

2. 856 pregnant women registered for ANC in this Primary health center and al the clients (100\%) were referred to the laboratory unit for routine ANC test including HBsAg test (Figure 1).

3. 850 (99.3\%) of these pregnant women did the test and continued ANC in this PHC, six of them (0.7\%) dropped out and did not do the test (Figure 2).

4. $778(91.5 \%)$ of these 850 were negative for HBsAg while $72(8.5 \%)$ tested positive (Figure 3).

5. All the $72(100 \%)$ positive patients were referred to a secondary health facility (Figure 4), for continuation of ANC and delivery in view of lack of facility for HBIG (Passive immunization of the new borne).

6. Two of the women still came in labour to the PHC and delivered successfully. The record showed that they received Hepatitis B vaccine (active immunization) and referred to the secondary health facility for further care in view of HBIG for the new borne (passive immunization).

7. The case notes of all these referred women did not show evidence of any follow-up whatsoever to the referral secondary health facility and no feedback were given them.

\section{Discussions}

The study revealed that about $99 \%$ of the clients were screened for HBsAg test in this center in the review year. This is a very good achievement, however $100 \%$ screening is desirable as recommended by CDC (2016) to prevent perinatal HBV transmission by identifying HBV-infected pregnant women and providing hepatitis B immune globulin and hepatitis B vaccine to their infants within 12 hours of birth. It is nevertheless, noted from the study that the roughly $1 \%$ of the clients (figure 2) who declined the test was due to lack of funds, therefore, the Nigerian Government needs to assist the poor clients who cannot afford this test to achieve $100 \%$ screening of the pregnant women for HBsAg. This is very pertinent because according to WHO (2016), hepatitis B is most commonly spread via mother to child at birth in highly endemic areas, furthermore, $80-90 \%$ of these infants infected during the first year of life develop chronic infections, thus, there is a great need to prevent this infection in these vulnerable group.

Moreover, a sero-prevalence of approximately 9\% (Figure 3) was found in this study, revealing that Karu environ is highly endemic for chronic hepatitis B infection especially among pregnant women. This is similar to the study by Zampino et.al (2015) who reported that Nigeria is among some African countries where HBV infection is hyper-endemic (greater than $8 \%$ of HBsAg chronic carriers in the general population). Therefore, robust preventive strategy need to be put in place in this center to protect the exposed neonates, as well as, public awareness campaign for the general public for screening and vaccination of seronegative clients especially as it concerns the high risk groups in accordance with World Health Organization's screening recommendation (WHO, 2015).

The study also found that all the pregnant women positive for HBsAg screening were referred to a secondary health facility (Figure 4), in accordance with the treatment guideline, since this PHC do not have capacity for administration of hepatitis B immune globulin to the exposed new born babies. According to Shiraki (2000) and CDC (2016), it is necessary to treat the infants of HBsAg positive mothers with hepatitis B immune globulin at birth, followed by HBV vaccination. These referrals were commendable good practice, but, on the other hand, no follow-up was made to ascertain whether the referred clients reported to the health facility and if they were given the required service. This is a gap in the service 
Texila International Journal of Public Health

Volume 4, Issue 4, Dec 2016

provision line identified from the study which must be urgently addressed by the facility Managers.

\section{Diagrams}

\section{Table 1. Age}

The age distribution of the ANC clients at the center in 2013 is between 14 and 43 as $\mathrm{g}$ given in table 1 . The results show the distribution of the age of respondents as $31 \%$ from age group of $25-29$ (highest), $29 \%$ for $20-24$ years, $20 \%$ for $30-34$ years, $15 \%$ for $14-19 y e a r s$ and $5 \%$ for 35-43years.

\begin{tabular}{|l|l|l|}
\hline AGE & FREQUENCY & PERCENT (\%) \\
\hline 14-19 YEARS & 129 & 15 \\
\hline 20-24 YEARS & 246 & 29 \\
\hline 25-29 YEARS & 266 & 31 \\
\hline 30-34 YEARS & 172 & 20 \\
\hline 35- 43 YEARS & 43 & 5 \\
\hline TOTAL & 856 & 100 \\
\hline
\end{tabular}

\section{Table 2. Occupation}

The occupation distribution of the ANC clients at the center in 2013 are as follows: Public Servants (45\%), Traders (22\%), House Wives (18\%) and Farmers (15\%).

\begin{tabular}{|l|l|l|}
\hline OCCUPATION & FREQUENCY & PERCENT (\%) \\
\hline HOUSE WIFE & 154 & 18 \\
\hline $\begin{array}{l}\text { PUBLIC } \\
\text { SERVANT }\end{array}$ & 385 & 45 \\
\hline FARMER & 128 & 15 \\
\hline TRADER & 189 & 22 \\
\hline TOTAL & 856 & 100 \\
\hline
\end{tabular}

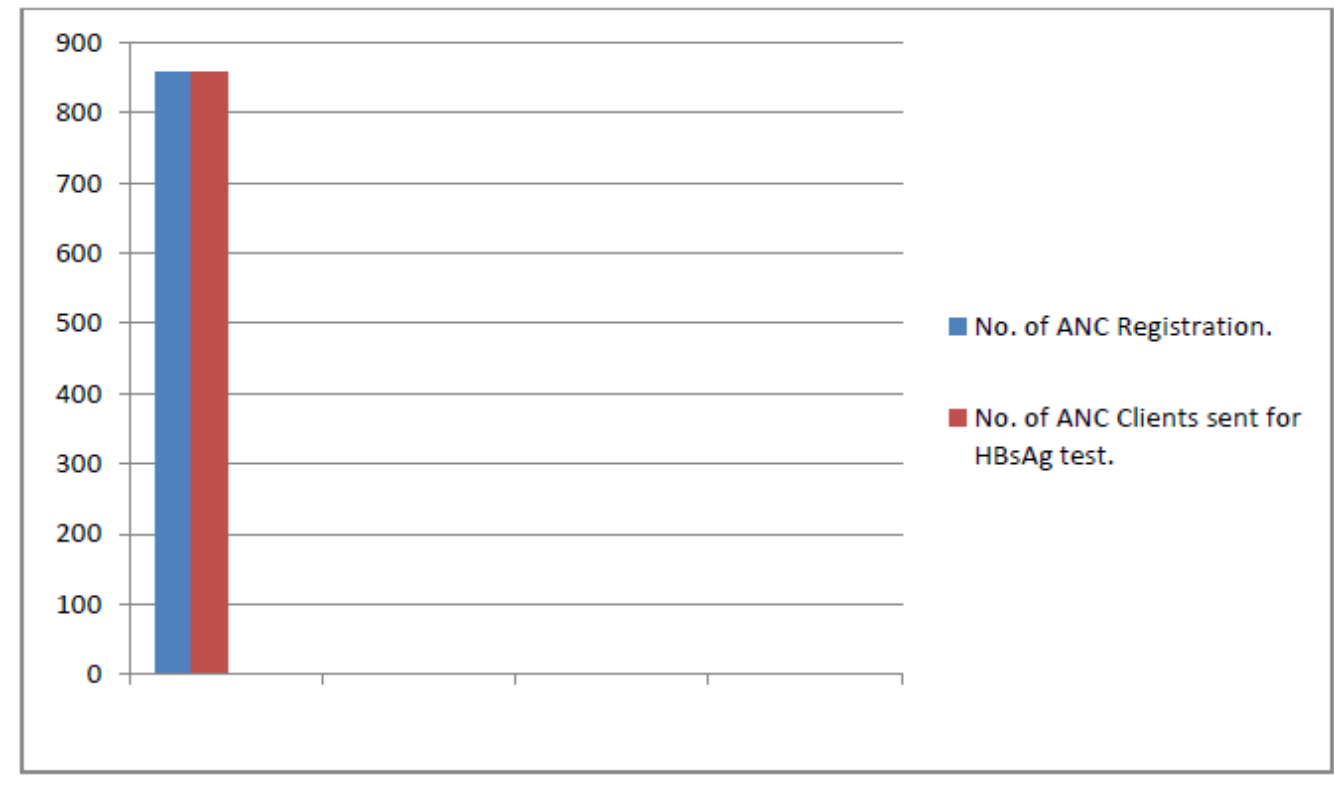

Figure 1.

Bar chart representing the number of ANC visit and number of ANC clients sent for HBsAg screening test at PHC Karu in 2013 (JAN.-DEC.). P1 $=856 / 856=100 \%$, P2= $856 / 856=100 \%$. 


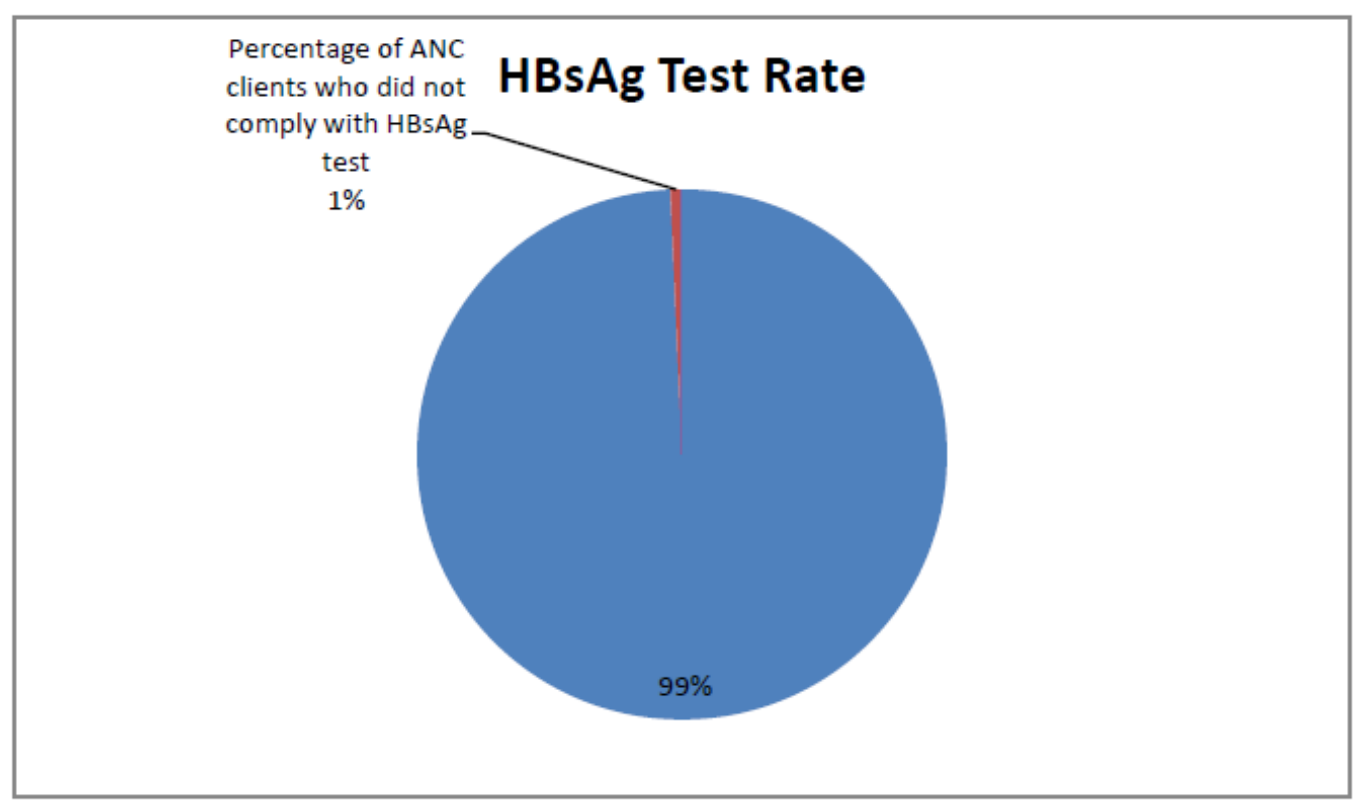

Figure 2.

Pie chart representing the percentage of ANC clients who did not do the HBsAg screening test offered them at PHC Karu, in 2013 (JAN.-DEC.). P= 6/856=0.7\% 1\%. About 99\% complied with thee test.

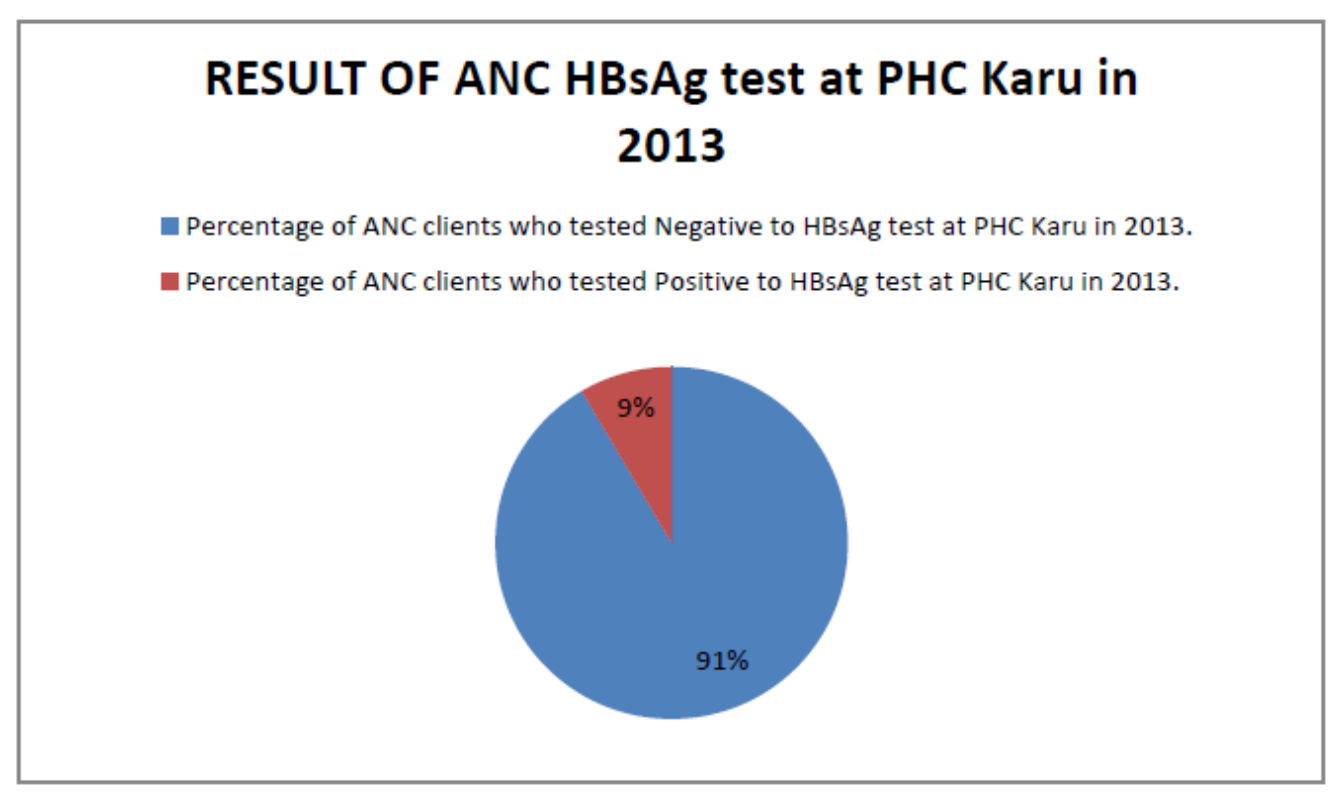

Figure 3

Pie chart representing the percentage of ANC Clients who tested negative and those who tested positive to HBsAg screening test at PHC Karu in 2013. $\mathrm{P}=72 / 850=8.5 \% \sim 9 \%$ (seropositive), $\mathrm{P}=778 / 850=91.5 \%$ (seronegative) 
Texila International Journal of Public Health

Volume 4, Issue 4, Dec 2016

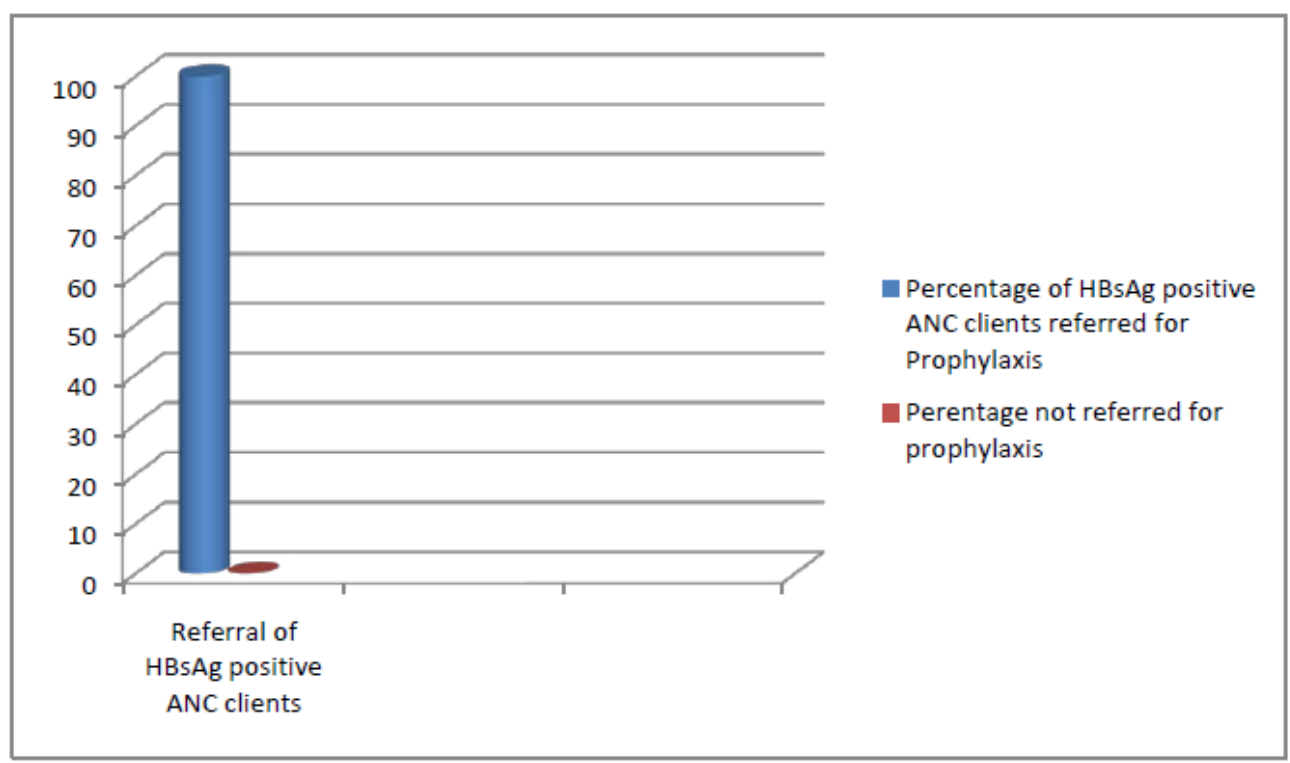

Figure 4

Column chart representing the percentage of ANC HBsAg-positive clients referred to a secondary health facility for prophylaxis for their new borne. $\mathrm{P}=72 / 72=100 \%$.

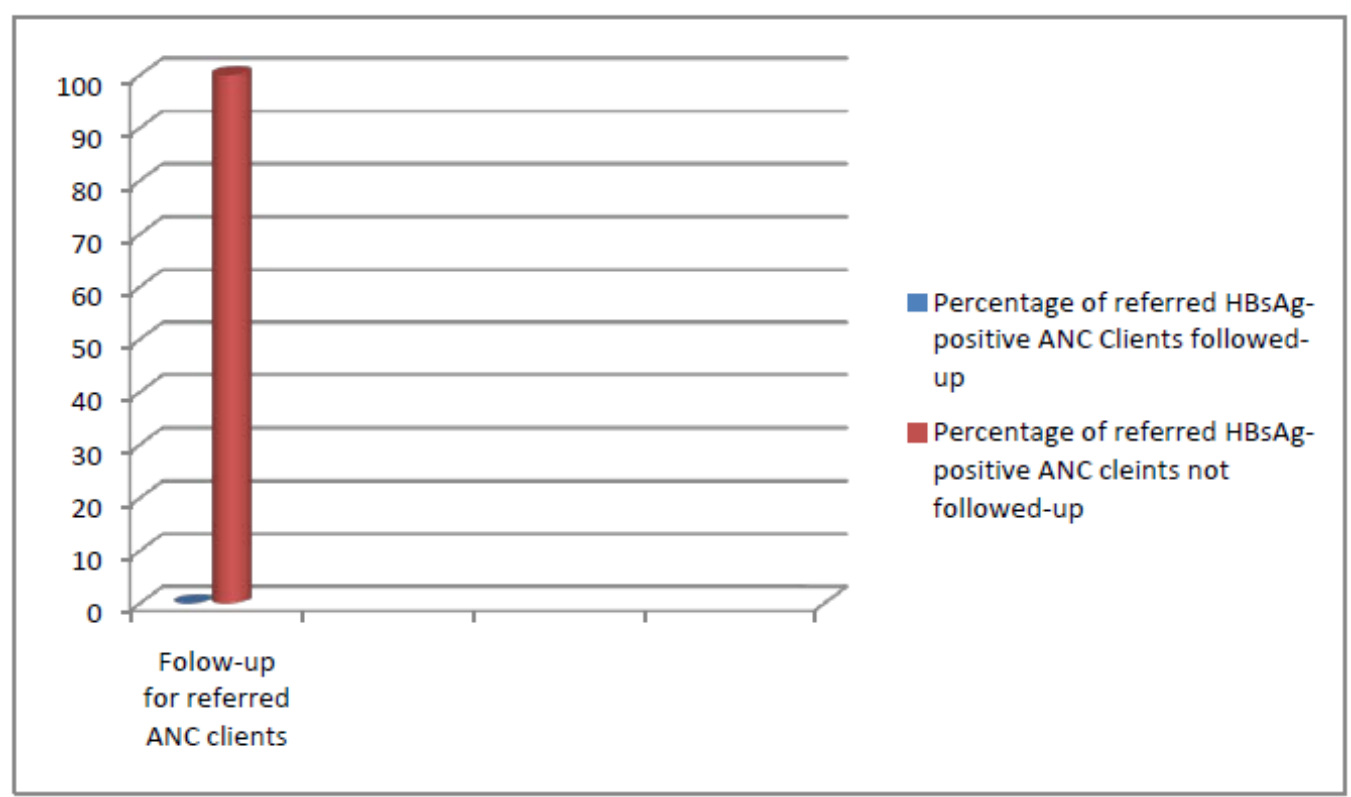

Figure 5

Column chart representing the percentage of Referred HBsAg-positive ANC clients that were followed-up after referral to a secondary health facility. $\mathrm{P}=0 / 72=0 \%$

\section{Conclusion}

The high endemic rate of $\mathrm{HBV}$ infection, (8.5\% prevalence) requires more effort at preventing the vertical transmission of HBV from seropositive clients to their newborns. The screening rate for ANC clients for HBsAg of 99.3\% s extremely commendable, nevertheless, $100 \%$ screening rate for all ANC clients is ideal, therefore, highly encouraged and zero follow-up for exposed infants with regards to HBIG prophylaxis is very poor and unacceptable practice. This goes to say that referral of all seropositive clients to a secondary health facility for prophylaxis for their newborns is a very good practice but should be followup to ensure that the services were rendered. 


\section{Recommendations}

In view of the findings from this study, the following are hereby recommended:

1. That the capacity of the PHC Karu be improved to Comprehensive PHC status such that more services like HBIG prophylaxis, caesarean section surgery etc., will be offered there.

2. That the traditional two-way referral system be institutionalized in the PHC such that follow-up of all referred cases is carried out for better service delivery to the patients.

3. That the HBsAg screening for pregnant women be made free of charge by the government to allow for all of them to access the service.

4. Further research at the secondary health facilities where these patients were referred to, in order to ascertain whether the prophylaxis guideline was strictly followed in managing these patients is strongly recommended.

\section{Limitations of the study}

The study was based on review of secondary data; therefore, any inadequacy/improper documentation of data could have introduced bias into the study.

\section{Acknowledgement}

My special thanks go to the officer in charge of PHC Karu, the nurses and midwives at the ANC section and the laboratory staff for their assistance and cooperation during this study.

\section{References}

[1]. Abdulsalami N., Tekena O. H., Sergei O. V, Germano M. R., Bernard B. A., Vitaly A. A. (1986) Prevalence of hepatitis B infection markers in representative areas of Nigeria. Intrn J Epiderm 1986; 15:274.

[2]. Aminu M.,Okachi E.E.,Abubarka S.M.,Yahaya A. Prevalence of hepatitis B virus surface antigen among asymptomatic students in a Nigerian University. Ann Afr Med [serial online] 2013 [cited 2014 Apr 4]; 12:55-6. Available from:

http://.annalsafrmed.org/text.asp?2013/12/55/108257.

[3]. Azubike J.C.,N kanginieme K.E.O. (1999). Paeditrics and child heath in a tropical region. Owerri Nigeria, African educational services.pp: 132.

[4]. CDC (2016). Viral hepatitis-hepatitis b, perinatal transmission, updated October, 2016. Accessed from: https://www.cdc.gov/hepatitis/hbv/perinatalxmtn.htm

[5]. Collier J., Longmore M., Scally P. (2003). Oxford handbook of clinical specialties, $6^{\text {th }}$ Ed. New Delhi, Oxford university press. Pp: 100,158.

[6]. Emechebe G O, Emodi I J, Ikefuna A N, Ilechukwu G C, Igwe W C, Ejiofor O S, Ilechukwu C A. Hepatitis B virus infection in Nigeria - A review. Niger Med J [serial online] 2009 [cited 2014 Apr 4];50:18-22. Available from: http://www.nigeriamedj.com/text.asp?2009/50/1/18/71932

[7]. Lin K, Vickery J. Screening for Hepatitis B Virus Infection in Pregnant Women: Evidence for the U.S. Preventive Services Task Force Reaffirmation Recommendation Statement. AHRQ Publication No. 09-05134-EF-3, June 2009.

http://www.uspreventiveservicestaskforce.org/uspstf09/hepb/hepbpgart

[8]. Lucas A.O.,Gilles H.M. (2003) Short textbook of public health medicine for the tropics, $4^{\text {th }}$ ed. London, Hodder Arnold. Pp:57-58

[9]. Park K. (2007) Park's textbook of preventive and social medicine, $19^{\text {th }}$ Ed. Jabalpur India, Bhanot publishers Pp:175-179

[10]. Longmore M.,Wilkinson I.,Torok E. (2001). Oxford handbook of clinical medicine, $5^{\text {th }}$ Ed. New York, Oxford university press. Pp:578-579

[11]. Shiraki K. (2000). Perinatal transmission of hepatitis B virus and its prevention. Journal of Gastroenterology/Hepatology, Suppl:E11-5.Accessed :.

https://www.ncbi.nlm.nih.gov/pubmed/10921375

[12]. World Health Organization (2014). Global alert response: Hepatitis B. Available from http://www.who.int/csr/disease/hepatitis/whocdscsrlyo20022/en/index2.html, accessed on 04/04/2014. 
Texila International Journal of Public Health

Volume 4, Issue 4, Dec 2016

[13]. World Health Organization (2015). Guidelines for the Prevention, Care and Treatment of Persons with chronic Hepatitis B infection. p46. Accessed from:

http://apps.who.int/iris/bitstream/10665/154590/1/9789241549059_eng.pdf?ua=1\&ua=1

[14]. World Health Organization (2016). Hepatitis Fact sheet, updated July 2016. Accessed from: http://www.who.int/mediacentre/factsheets/fs204/en/

[15]. Zampino R., Boemio A., Sagnelli C., Alessio L., Adinolfi L.E., Sagnelli E., and Coppola N. (2015). Hepatitis B virus burden in developing countries. World Journal of Gastroenterology, 21(42):

11941-11953. Accessed from: https://www.ncbi.nlm.nih.gov/pmc/articles/PMC4641116 